\title{
Antioxidant Activity of the Leaf Extract of Clerodendrum volubile (Verbenaceae)
}

\section{Salahudeen and Abdulazeez Bolaji*}

Department of Pharmaceutical and Medicinal Chemistry, Faculty of Pharmacy, Olabisi Onabanjo University, Sagamu, Ogun State, Nigeria *Corresponding Author: Abdulazeez Bolaji, Department of Pharmaceutical and Medicinal Chemistry, Faculty of Pharmacy, Olabisi Onabanjo University, Sagamu, Ogun State, Nigeria.

Received: March 18, 2019; Published: May 03, 2019

DOI: $10.31080 /$ ASPS.2019.03.0271

\begin{abstract}
Clerodendrum volubile belongs to the family Verbenaceae commonly known as the verbena family or vervain family. The aim of this study was to verify the antioxidant activity of the n-hexane fraction of the leave extract.

The plant was collected and authenticated. The leaves were washed, dried and blended. The blended leaves were then subjected to phytochemical analysis using standard methods to screen for the presence of saponin glycosides, tannins, alkaloids, anthraquinone glycosides and flavonoids. Extraction was carried out with acetone using the Soxhlet apparatus. The extracts were concentrated using the rotary evaporator and weighed. Vacuum Liquid Chromatographic technique was then employed to partition the extract into three fractions of n-hexane, ethylacatate and methanol. Column chromatography was then carried out on the n-hexane fraction and the eluate collected into different collecting bottles. The eluates were then combined together into different fractions based on their Rf values. The fractions were then spotted on pre-coated silica gel plates and sprayed with 2, 2- diphenyl-1-picrylhydrazyl (DPPH) in a fume cupboard.

The phytochemical screening showed the presence of anthraquinone glycosides, flavonoid, alkaloids and saponin glycosides. The pre-coated silica gel plates which have been spotted with the fractions of the leaf extracts of Clerodendrum volubile sprayed with DPPH showed the presence of antioxidant activity.

The study showed that the n-hexane extract of the leaves of Clerodendrum volubile has antioxidant activity.

Keywords: Clerodendrum volubile; Antioxidant; DPPH; Chromatography
\end{abstract}

\section{Introduction}

Taxonomy of verbenaceae

The Verbenaceae is a family, commonly known as the verbena family or vervain family, of mainly tropical flowering plants. It contains trees, shrubs and herbs notable for heads, spikes, or clusters of small flowers, many of which have an aromatic smell (Stevens, 2012).

Recent phylogenetic studies have shown that numerous genera traditionally classified in Verbenaceae belong instead in Lamiaceae. The new narrowly circumscribed Verbenaceae family includes some 35 genera and 1,200 species [1]. The mangrove genus Avicennia, sometimes placed in the Verbenaceae or in its own family, Avicenniaceae, has been placed in the Acanthaceae.

\section{Antioxidants}

It is ironic that oxygen, an element indispensable for life [2] under certain situations has deleterious effects on the human body [3]. Antioxidants are, without a doubt, an essential part of optimal health. Even conventional Western physicians now acknowledge the significance of getting sufficient antioxidants from diet or taking high-quality antioxidant supplements.

An antioxidant is a molecule stable enough to donate an electron to a rampaging free radical and neutralize it, thus reducing its capacity to damage. These antioxidants delay or inhibit cellular damage mainly through their free radical scavenging property [4]. These low- molecular-weight antioxidants can safely interact with free radicals and terminate the chain reaction before vital mole- 
cules are damaged. Examples of such antioxidants are glutathione, ubiquinol, and uric acid which are produced during normal metabolism in the body [5]. Other antioxidants are found in the diet. Although there are several enzyme systems within the body that scavenge free radicals, the principal micronutrient (vitamins) antioxidants are vitamin E ( $\alpha$-tocopherol), vitamin C (ascorbic acid), and B-carotene [6]. The body cannot manufacture these micronutrients, so they must be supplied in the diet. In addition, the body's natural antioxidant production declines as one age.

\section{Literature Review}

Erukainure., et al. [7] reported the phytochemical properties of the leaves of Clerodendrum volubile as well as its in vitro antioxidant activities. The nutritional qualities of the leaves of Clerodendrum volubile indicating high contents of vitamin A, manganese, iodine, and zinc was also reported by Erukainure., et al [8]. A moderate biological values of the leaves, but higher values of true digestion, protein efficiency ratio and net protein utilization were also reported [7].

The anti-inflammatory activity of the leaf extracts of Clerodendrum volubile was established by Fred-Jaiyesinmi., et al. (2015) using a non-steroidal (NSAID) model of fresh albumin- induced rat paw oedema. The study revealed that the activity exhibited by the methanol, ethyl acetate and petroleum ether extracts were more pronounced than that exhibited by the reference drug (diclofenac sodium) which confirmed that the constituents in the methanol, petroleum ether and ethyl acetate of Clerodendrum volubile acted like most clinically effective anti-inflammatory drugs [8]. This antiinflammatory effect reported in the study by Fred-Jaiyesinmi., et al. (2015) and that reported in other Clerodendrum species suggested that Clerodendrum species may be a possible source of novel anti inflammatory drugs and this study on Clerodendrum volubile therefore justifies the use of Clerodendrum volubile as an anti inflammatory agent in folklore medicine [10].

Clerodendrum volubile has been reported to contain very huge quantity of iron and zinc; elements which are important in many enzymes for their functions and for the maintenance of fresh skin. The presence of phenolic compounds and other phytochemicals has also been observed [11]. When consumed, the leaves are often noted for stimulating lost appetite as well as replenishing vitality for mothers of new born babies [11].

\section{Materials and Methods}

Equipment

Electronic weighing balance (OHAUR corporation), Rotary evaporator (Astell), Glass column, Thin layer chromatography pre- coated plates, $30 \mathrm{ml}$ collecting bottles, evaporating dishes, beakers, measuring cylinders and capillary tubes.

Chemicals and reagents

$\mathrm{N}$-hexane; ethylacetate; methanol; acetone (BDH chemicals limited, Pole England), Silica gel (Labtech chemicals, USA), 2, 2-diphenyl-1-picrylhydrazl (DPPH) (Indonesia).

\section{Methodology}

\section{Collection of samples}

The plant, Clerodendrum volubile, was collected at Arapaja, Odo Ona Kekere, Old Lagos road, Ibadan Oyo State in 2016. Botanical authentication was done at the Forestry Research Institute of Nigeria (FRIN), Ibadan Oyo state. Voucher samples were prepared and a voucher number, 14010, was assigned.

\section{Drying procedure}

The leaves of Clerodendrum volubile plant were air dried for a period of 20 days. The leaves were then milled and kept in containers for preservation.

\section{Preliminary phytochemical screening}

The powdered sample was screened for the following secondary metabolites using standard methods [12].

Test for anthraquinone glycosides

- Test for free anthraquinones: $0.5 \mathrm{~g}$ of the powdered leaves of Clerodendrum volubile was placed in a test tube and $5 \mathrm{ml}$ of chloroform was added and shaken for $5 \mathrm{~min}$ utes and then filtered. An equal volume of $10 \%$ ammonia solution was then mixed with the filtrate. The formation of a bright pink colour in the aqueous layer shows the presence of free anthraquinones.

- Test for combined anthraquinones: $1.0 \mathrm{~g}$ of the powdered leaves of Clerodendrum volubile was boiled in $2 \mathrm{ml}$ of $10 \% \mathrm{HCl}$ for minutes; the extract was filtered while hot and allowed to cool. The filtrate was partitioned against equal volumes of chloroform. By means of a pipette, the chloroform layer was transferred to a clean test tube and the $10 \%$ ammonia solution was added to it and shaken. The formation of a delicate rose pink colour in the aqueous layer showed the presence of combined anthraquinones.

\section{Test for flavonoids}

$1.0 \mathrm{~g}$ of the powdered leaves of Clerodendrum volubile was boiled with $10 \mathrm{ml}$ of water for 5 minutes, filtered while hot and allowed to cool. To the filtrate was added the following reagents:

- 2 mls of sodium hydroxide solution. A yellow colouration indicated the presence of flavonoid in the sample. 
- $\quad 5 \mathrm{ml}$ dilute ammonia solution to $5 \mathrm{ml}$ of the aqueous filtrate and conc. $\mathrm{H}_{2} \mathrm{SO}_{4}$ was added to it. The presence of a light brown colour at the bottom and a reddish interface which disappeared on standing suggested the presence of flavonoids in the sample.

Test for saponin glycosides

To $1 \mathrm{~g}$ of the powdered leaves of Clerodendrum volubile was added $10 \mathrm{ml}$ of distilled water and boiled for 10 minutes. The extract was then filtered while hot and the filtrate allowed to cool. The following were then carried out on the filtrate:

- Frothing activity: $2.5 \mathrm{ml}$ of the filtrate was diluted to $10 \mathrm{ml}$ with distilled water and shaken vigorously for minutes. The formation of frothing on the sample showed the presence of saponin glycosides.

- Emulsifying properties: To about $5 \mathrm{ml}$ of the filtrate, 2 drops of arachis oil was added and was vigorously shaken. The formation of a stable emulsion suggested the presence of saponin glycosides.

Test for alkaloids

$1.0 \mathrm{~g}$ of the powdered leaves of Clerodendrum volubile was added to $10 \mathrm{ml}$ of $10 \% \mathrm{HCl}$ and heated on a water bath for 10 minutes. The extract was filtered and the $\mathrm{PH}$ was adjusted to $6-7$. Then, $0.5 \mathrm{ml}$ of the filtrate was taken and small quantities of the following reagents were added and mixed in a test tube: Dragendorff's reagent, $1 \%$ picric acid solution. The formation of a precipitate of characteristic colour indicates the presence of an alkaloid.

\section{Test for tannins}

$1.0 \mathrm{~g}$ of the powdered leaves of Clerodendrum volubile was added to $10 \mathrm{ml}$ of water for 5 minutes, it was allowed to cool and then filtered. To $1 \mathrm{ml}$ of the solution in a test tube, diluted to $5 \mathrm{mls}$ with water, a few drops of ferric chloride $(0.1 \%)$ were added. Also, $1 \mathrm{ml}$ of the filtrate was diluted to $5 \mathrm{ml}$ with water and few drop of bromine water added. Also, few drops of lead acetate and aqueous potassium dichromate were added to $1 \mathrm{ml}$ of the filtrate in separate test tubes. The formation of precipitate and colour change indicated the presence of tannins.

\section{Extraction procedure}

$120 \mathrm{~g}$ of powdered leaves of Clerodendrum volubile was extracted with $1350 \mathrm{ml}$ of acetone using a Soxhlet apparatus. The extract was then partitioned with n-hexane, ethylacetate and methanol using Vacuum Liquid Chromatography. The different extracts obtained were then concentrated using a rotary evaporator operating at $50^{\circ} \mathrm{C}$ and the concentrated extracts were weighed and stored in an evaporating dish prior to analysis.

\section{Vacuum liquid chromatography (VLC)}

The VLC apparatus was packed with $60 \mathrm{~g}$ of silica gel $60-120$ mesh size and $12.60 \mathrm{~g}$ of the acetone extract was loaded. $400 \mathrm{ml}$ of n-hexane was then added and the pump opened. This was then repeated with $400 \mathrm{ml}$ of ethylacetate and $400 \mathrm{ml}$ of methanol. These were then concentrated. TLC was carried out on all the fractions by spotting from the different fractions of the Clerodendrum volubile extracts on the TLC plate using a mobile phase combination of hexane: ethylacetate: methanol (8:1.5:0.5) and hexane: chloroform: ethylacetate $(7: 2: 1)$ and both plates were sprayed with vanillin sulphuric acid.

\section{Column chromatography}

A $3 \mathrm{~cm}$ by $75 \mathrm{~cm}$ column was packed with $100 \mathrm{~g}$ of $60-120$ mesh size silica gel moistened with $100 \% \mathrm{n}$-hexane. The n-hexane fraction of the extract of Clerodendrum volubile was then mixed with dry silica gel and added to the packed silica gel. Starting with $100 \%$ n-hexane, the column was then eluted followed by $90 \%$ n-hexane and $10 \%$ ethylacetate. While decreasing the $n$-hexane by a fraction of $10 \%$ and increasing that of ethylacetate correspondingly, a $100 \%$ ethylacetate was achieved. This was then followed with a decreasing level of ethylacetate by $10 \%$ and increasing level of methanol by $10 \%$ also to form the mobile phase. $20 \mathrm{ml}$ of the eluate fractions was collected in different bottles and the solvent was allowed to evaporate. The fractions of the extracts were spotted on TLC plates and developed using n-hexane: ethylacetate: methanol (8:1.5:0.5) as the mobile phase. The TLC plates were then viewed under ultraviolet light at $254 \mathrm{~nm}$ and $366 \mathrm{~nm}$. The extract with similar Rf values were pooled together to give eight fractions.

\section{Antioxidant activity}

$0.2 \%(\mathrm{w} / \mathrm{v})$ of 2, 2-diphenyl-1-picrylhydrazyl (DPPH) was dissolved in $50 \mathrm{ml}$ of methanol and made up to volume in a $100 \mathrm{ml}$ standard flask. It was then poured into a sprayer. The n-hexane fraction was spotted on three different chromatoplates. Plate 1 (as shown in figure 1) was immersed in a chromatographic tank with a solvent combination of n-hexane: ehylacetate: methanol of 8:1.5:0.5 and allowed to develop. Plate 2 (as shown in figure 2) was immersed in a chromatographic tank with a solvent combination of ethanol: methanol: water of 8:1.5:0.5 and allowed to develop. Plate 3 (as shown in figure 3) was immersed in a chromatographic tank with a solvent combination of benzene: ethylacetate: ammonia of 9:1:0.1. 
The plates were then dried in the oven and sprayed with the dissolved 2, 2-diphenyl-1-picrylhydrazyl (DDPH) in a fume cupboard. Any corresponding yellow spot on a purple background was then noted and the picture of the chromatoplate taken.

\section{Determination of the extract percentage yield}

The yield of the different extracts was weighed and the percentage yield was calculated using the formula below and recorded. Percentage yield $=$ qe $/$ qps $\times 100 \%$
Where

$\mathrm{qe}=$ quantity of extract in gram

qps= quantity of powder sample in grams

\section{Results}

The percentage yield of powdered leaves of Clerodendrum volubile for acetone was $10.5 \%$, n-hexane was $26.91 \%$, ethylacetate was $45.24 \%$ and methanol was $27.85 \%$ (table 1 ).

\begin{tabular}{|l|c|c|c|c|c|}
\hline Plant part & $\begin{array}{c}\text { Weight of } \\
\text { sample }\end{array}$ & $\begin{array}{c}\text { Acetone extract } \\
\text { yield (yield \%) }\end{array}$ & $\begin{array}{c}\text { N-Hexane extract } \\
\text { yield (yield \%) }\end{array}$ & $\begin{array}{c}\text { Ethylacetate extract } \\
\text { yield (yield \%) }\end{array}$ & $\begin{array}{c}\text { Methanol extract yield } \\
\text { (yield \%) }\end{array}$ \\
\hline Leaf & $120 \mathrm{~g}$ & $12.60 \mathrm{~g}(10.5 \%)$ & $3.39 \mathrm{~g}(26.91 \%)$ & $5.70 \mathrm{~g}(45.24 \%)$ & $3.51(27.85 \%)$ \\
\hline
\end{tabular}

Table 1: Table showing the percentage yield of the acetone, n-hexane, ethylacetate and methanol from Clerodendrum volubile.

The preliminary phytochemical screening of the leaves of Clerodendrum volubile revealed the presence of anthraquinone, flavonoid, saponin, and alkaloid (table 2).

\begin{tabular}{|c|c|}
\hline Test & Inference \\
\hline Anthraquinone & + \\
\hline Flavonoid & + \\
\hline Saponin & + \\
\hline Alkaloid & + \\
\hline Tannin & - \\
\hline
\end{tabular}

Table 2: Table showing the phytochemical screening of the leaves of Clerodendrum volubile

$$
\begin{aligned}
\text { Key: }+ & =\text { Present } \\
- & =\text { Absent }
\end{aligned}
$$

The n-hexane fraction of the leaf extract of Clerodendrum volubile on thin layer chromatography (TLC) plates sprayed with 2 2-diphenyl-1-picrylhydrazyl using n-Hexane: Ethylacetate: Methanol (8:1.5:0.5) solvents (figure 1) was observed to show a yellow color on the purple background.

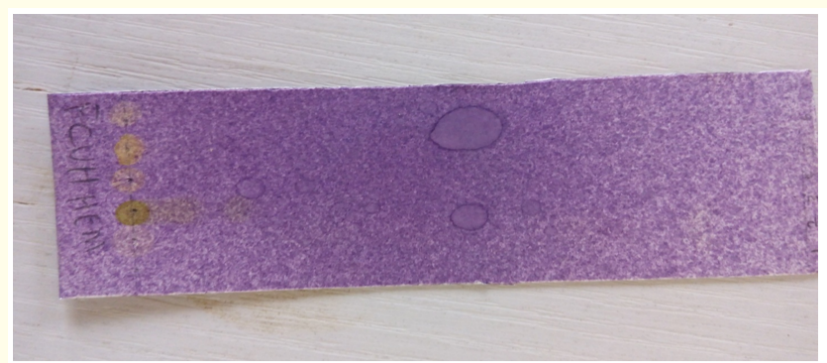

Figure 1: Image showing the antioxidant activity of the n-hexane fraction of the leaf extract of Clerodendrum volubile on thin layer chromatography (TLC) plates sprayed with 2, 2-diphenyl-1-picrylhydrazyl using n-Hexane: Ethylacetate: Methanol (8:1.5:0.5) solvents.

The n-hexane fraction of the leaf extract of Clerodendrum volubile on thin layer chromatography (TLC) plates sprayed with 2, 2-diphenyl-1-picrylhydrazyl using Ethanol: Methanol: Water
(8:1.5:0.5) as solvents (figure 2) was observed to show a yellow color on the purple background.

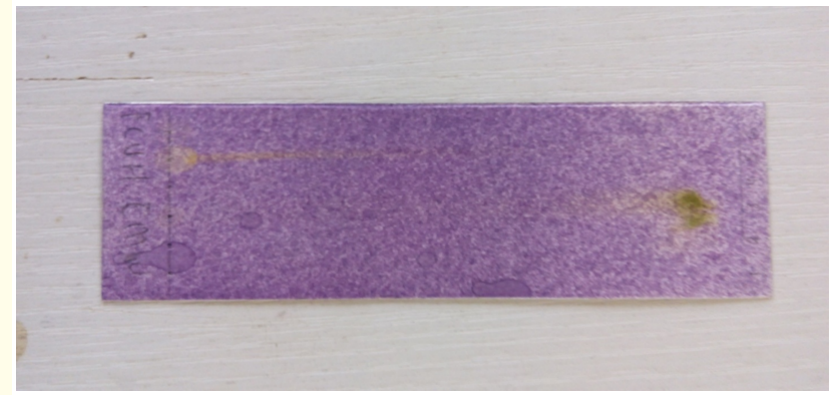

Figure 2: Image showing the antioxidant activity of the n-hexane fraction of the leaf extract of Clerodendrum volubile on thin layer chromatography (TLC) plates sprayed with 2, 2-diphenyl1-picrylhydrazyl using Ethanol: Methanol: Water (8:1.5:0.5) as solvents.

The N-hexane fraction of the leaf extract of Clerodendrum volubile on thin layer chromatography (TLC) plates sprayed with 2, 2-diphenyl-1-picrylhydrazyl using Benzene: Ethylacetate: Ammonia (9:1:0.1) solvents (figure 3) was observed to show a yellow color on the purple background.

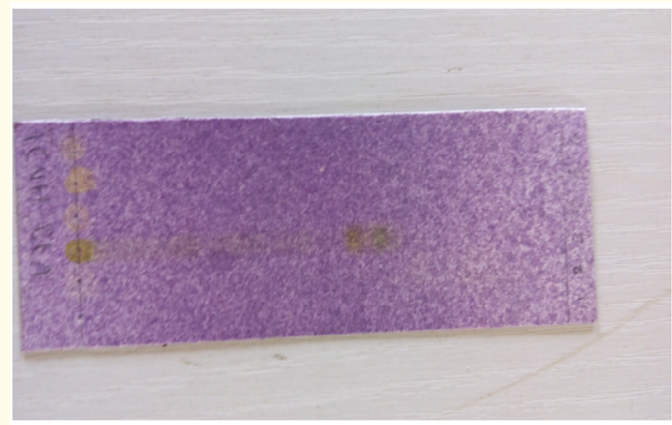

Figure 3: Image showing the antioxidant activity of the N-hexane fraction of the leaf extract of Clerodendrum volubile on thin layer chromatography (TLC) plates sprayed with 2, 2-diphenyl-1-picrylhydrazyl using Benzene: Ethylacetate: Ammonia (9:1:0.1) solvents. 


\section{Discussion and Conclusion}

\section{Discussion}

The result obtained from the extraction process of the leaves of Clerodendrum volubile using the Soxhlet apparatus gave a $10.5 \%$ yield which indicated a very low yield.

The partitioning of the different fractions of the leaf extract of Clerodendrum volubile gave different percentage (\%) yield: n-hexane gave $26.91 \%$ yield, ethylacetate gave $45.24 \%$ yield and Methanol gave $27.85 \%$ yield (as shown in table 1 ). This shows that the ethylacetate fraction has the highest yield. This is in conformity to study by Fred-Jaiyesinmi (2015) where the ethylacetate fraction has the highest anti-inflammatory activity.

The result obtained from the phytochemical screening (as seen in table 2) is in agreement to the studies carried out by Dinesh., et al. [13] and Devi., et al [14].

The phytochemical screening showed that the leaf contains flavonoid (polyphenollic compounds) which possesses antioxidant property, hence the antioxidant property shown by the leaves of Clerodendrum volubile could be due to the flavonoid constituent present in the plant. This result is in consonance to the study by Erukainure et al., [7] on the total flavonoid content of the leaves of Clerodendrum volubile.

The yellow coloration observed on the TLC plates spotted with n-hexane fraction of the n-hexane leaf extract of Clerodendrum volubile sprayed with 2, 2-diphenyl-1-picrylhydrazyl (as shown in figures 1,2, and 3) showed that the n-hexane fraction has antioxidant activity which correlates with the work carried out by Erukainure., et al. [7] thus can serve as a source of natural antioxidant if further work is carried out [15].

\section{Conclusion}

The study showed that the leaf extract of Clerodendrum volubile has antioxidant activity which can act as primary or secondary antioxidant.

\section{Acknowledgement}

I thank God Almighty for making this a reality. Also I am grateful to my supervisor, Mr. Fagbohun Ayodele B., my parents, my siblings and Mr. Ben Ndimele for the support.

\section{Bibliography}

1. Heywood VH., et al. "Flowering Plant Families of the World". Royal Botanic Gardens, Kew. (2007): 56-58.

2. Mohammed AA and Ibrahim AA. "Pathological roles of reactive oxygen species and their defence mechanism". Saudi Pharm Journal 12 (2004): 1-18.
3. Bagchi K and Puri S. "Free radicals and antioxidants in health and disease". East Mediterranean Health Journal 4 (1998): 350-360.

4. Halliwell B. "How to characterize an antioxidant- An update". Biochemical Society Symposia 61 (1995): 73-101.

5. Shi HL., et al. "Comparative study on dynamics of antioxidative action of $\alpha$ - tocopheryl hydroquinone, ubiquinol and $\alpha$ tocopherol, against lipid peroxidation". Free Radical Biology and Medicine 27 (1999): 334-346.

6. Levine M., et al. "Criteria and recommendation for Vitamin C intake”. JAMA 281 (1991): 1415-1423.

7. Erukainure OL., et al. "Nutritional evaluations of Clerodendrum volubile, a tropical nonconventional vegetable as sole dietary protein source in rats". International Journal of Biological and Medical Research 2 (2011): 374-377.

8. Erukainure OL., et al. "Nutritional qualities and phytochemical constituents of Clerodendrum volubile, a tropical nonconventional vegetable". International Food Research Journal 18 (2011): 1393-1399.

9. Vinegar R., et al. "Biphasic development of carrageenin oedema in rats". Journal of Pharmacology and Experimental Therapeutics 166 (1969): 96-103.

10. Fleischer TC., et al. "Antimicrobial and Antiiflammatory activities of Clerodendrum splendens leaves". Pharmacognosy Research 1 (2011): 85-89.

11. Adefegha SA and Oboh G. African Journal of Pharmacy and Pharmacology 7.3 (2013): 332-346

12. Trease and Evans, (2002).

13. Dinesh K., et al. "Macroscopical and Microscopical evaluation of leaves of Clerodendrum inerme Gaertn". International Journal of Biomedical Science 2.1 (2011): 404-408.

14. Devi VG., et al. "Pharmacognostic and Antioxidant studies on Clerodendrum inerme and identification of ursolic acid as marker compound". International Journal of Pharmacy and Pharmaceutical Sciences 4.2 (2011): 145-148.

15. WHO. Traditional medicine strategy 2002-2005. World health report, World Health Organization (2002).

\section{Volume 3 Issue 6 June 2019}

(C) All rights are reserved by Salahudeen and Abdulazeez Bolaji. 